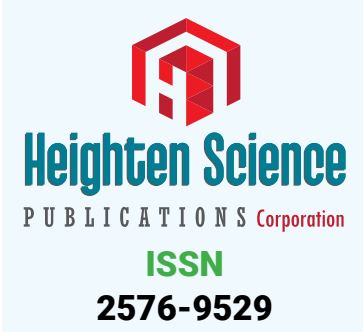

*Address for Correspondence: Islam Omar Mohamad Amin Elshazly, Faculty of Medicine Ain Shams University, Cairo, Egypt, Email: Islamony2006@hotmail.com

Submitted: 20 November 2017 Approved: 20 December 2017 Published: 21 December 2017

Copyright: @ 2017 Sarhan II. et al. This is an open access article distributed under the Creative Commons Attribution License, which permits unrestricted use, distribution, and reproduction in any medium, provided the original work is properly cited.
Thesis

\section{Short term effect of Intravenous Intermittent Iron Infusion versus Bolus Iron Infusion on Iron} parameters in Hemodialysis patients

\author{
Iman Ibrahim Sarhan ${ }^{1}$, Hussein Sayed Hussein², Islam Omar \\ Elshazly ${ }^{2 *}$ and Mahmoud Salah Hassan ${ }^{3}$ \\ 'Professor of Internal Medicine and Nephrology, Faculty of Medicine Ain Shams University, \\ Egypt \\ ${ }^{2}$ Lecturer of Internal Medicine and Nephrology, Faculty of Medicine Ain Shams University, Egypt \\ ${ }^{3}$ M.B, B.ch, Egypt
}

\section{Abstract}

Intravenous iron is used in combination with erythropoi esis-stimulating agents to treat the anemia of hemodialysis patients, however, there is variety in the dose and the frequency. So we compare bolus intravenous iron administration protocol vs an intermittent intravenous iron infusion protocol for 3 months in a single blinded design that was conducted on 30 patients randomized into 2 matching groups. Iron parameter, hemoglobin level, and CRP were monitored before and at the end of study. Patients with end stage renal disease on regular hemodialysis with iron deficiency anemia can be treated with intravenous iron administration either by the protocol of divided doses of IV iron through the sessions of hemodialysis or by giving the total dose of iron needed as a single large dose on only one session of hemodialysis, obtaining the same outcome in correction of iron parameters in treatment of iron deficiency anemia.

\section{Introduction}

Anemia is common among patients with ESRD and associated with increased morbidity, mortality, and risk of hospitalization [1]. The anemia of ESRD is managed primarily with erythropoiesis-stimulating agents (ESAs) and intravenous (IV) iron supplements [2]. Recent safety concerns about ESAs [3,4] as well as changes in reimbursement policies in Medicare's ESRD program have led to increased reliance on IV iron for the management of anemia $[5,6]$.

Iron supplementation is widely used in HD patients to treat iron deficiency, prevent its development in ESA-treated patients, reduce the ESAs dose and raise the Hb levels in the presence or absence of ESAs treatment, so its use has been increased last years $[7,8]$. The trend to greater use of iron is reinforced by evidence suggesting that more frequent iron use decreases ESA requirements in patients with treatment-refractory anemia $[9,10]$. Iron treatment strategies have been reported to vary substantially among clinicians [11-13]. Some nephrologists administer large repletion doses of iron over consecutive dialysis sessions on an intermittent, as-needed basis [11]. Others physicians instead provide low-dose administrations of iron (maintenance dosing) every 1-2 weeks to maintain iron stores. Currently, there is little evidence regarding the effectiveness of these different approaches to iron supplementation.

\section{Aim of the work}

This randomized controlled study has been initiated to investigate whether 
intermittent intravenous iron intake differs from a protocol of total dose correction iron administration, in terms of achieved $\mathrm{Hb}$ level or iron parameters and EPO requirement.

\section{Method}

This was a randomized controlled study that was conducted on 30 adult chronic hemodialysis patients, on regular dialysis thrice weekly with acceptable urea reduction rate more than $65 \%$ who have iron deficiency anemia, with a stable hemoglobin and had no background of hematological disorder. They were divided into 2 groups: Group A \& Group B matching number, age, gender of the patients, dialysis duration \& type of vascular access used. Group A included 15 patients having a bolus intravenous iron administration protocol compared with Group B included 15 patients having an intermittent intravenous iron infusion protocol for 3 months. Patients with malignancy, recent history of bleeding, liver, thyroid, or infectious diseases, alterations in leucocyte count or formula, concurrent sepsis and/or treatment with steroids or immunosuppresses were excluded. In addition to recording demographic data, (Table 1) pre and post-study measurements of hemoglobin and Serum ferritin (ng/ml), Serum iron (mcg/ml), Total Iron Binding capacity TIBC (mcg/dl), TSAT (\%) levels\& CRP (mg/ dl) were recorded.

Amount of iron required by (mg) throughout the study was measured by following equation (Target $\mathrm{Hb}$-Patient $\mathrm{Hb}$ ) g/l X body weight $\{\mathrm{kg}\} \mathrm{X} 0.24+$ Iron stores $\{\mathrm{mg}\} 500$ is recommended for iron stores in patients have body weight above $30 \mathrm{~kg}$ (www. medicines.org.uk/emc/ medicine/14139). These patients were closely observed for adverse reaction such as metallic taste, fever, hypotension, pruritis, phlebitis, dyspnea, nausea, vomiting and anaphylaxis. Any adverse events were recorded either during or immediately after the injection up to 30 minutes. The patient was also advised to contact the unit if they developed any subsequent symptoms.

\section{Statistical Methods}

Data were analyzed using PASW version 18 (IBM(C) Corp., Armonk, NY, USA). Normality of data was tested using D'Agostino-Pearson test, normally distributed numerical variables were presented as mean \pm SD. Numerical data were compared using unpaired t test. Degree of change of different parameters was calculated as follows ((After-Before)/before), to calculate the ratio of change in reference to the baseline reading of each parameter (Table 2).

\section{Results}

Study was conducted on 30 patients randomized into 2 groups to receive either bolus iron infusion or intermittent iron therapy in a single blinded design, iron parameter, hemoglobin level, and CRP were monitored at the start and the end of study for change. In both groups there were a significant increase in hemoglobin level, TSAT (\%) \& ferritin level without significant change in CRP titer.

\begin{tabular}{|c|c|c|c|c|}
\hline & & Bolus & Intermittent & P Value \\
\hline \multicolumn{2}{|c|}{ Age (Years) } & $42 \pm 11$ & $41.8 \pm 12$ & 0.645 \\
\hline \multirow{2}{*}{ Gender } & Male & $9(60 \%)$ & $8(53.3 \%)$ & \multirow{2}{*}{0.713} \\
\hline & Female & $6(40 \%)$ & $7(46.7 \%)$ & \\
\hline \multicolumn{2}{|c|}{ Duration on dialysis (Years) } & $4 \pm 2.8$ & $4.3 \pm 1.5$ & 0.54 \\
\hline \multicolumn{2}{|c|}{ HTN } & $7(46.7 \%)$ & $8(53.3 \%)$ & 0.87 \\
\hline \multicolumn{2}{|c|}{ DM } & $9(60 \%)$ & $10(66.7 \%)$ & 0.76 \\
\hline \multirow{3}{*}{ Vascular Access } & AVF & $9(60 \%)$ & $10(66.7 \%)$ & \multirow{3}{*}{0.074} \\
\hline & AVG & $4(26.7 \%)$ & $5(33.3 \%)$ & \\
\hline & Access & $2(13.3 \%)$ & 0 & \\
\hline
\end{tabular}


Table 2: Comparison between groups as regard percent of change of different parameters in reference to their baseline.

\begin{tabular}{|c|c|c|c|c|c|}
\hline \multirow{3}{*}{$\%$ of change from baseline } & \multicolumn{4}{|c|}{ Group } & \multirow{3}{*}{ P Value } \\
\hline & \multicolumn{2}{|c|}{ Bolus Iron } & \multicolumn{2}{|c|}{ Intermittent Iron } & \\
\hline & Mean & \pm SD & Mean & \pm SD & \\
\hline Delta $\mathrm{Hb}$ & 41.79 & 9.48 & 38.92 & 8.17 & .383 \\
\hline Delta Iron & 121.47 & 92.88 & 105.52 & 108.96 & .669 \\
\hline Delta TIBC & -6.64 & 28.38 & -9.60 & 31.63 & .790 \\
\hline Delta TSAT & 137.66 & 77.81 & 122.30 & 62.35 & .556 \\
\hline Delta Ferritin & 145.02 & 40.88 & 146.62 & 45.65 & .920 \\
\hline Delta CRP & -12.02 & 35.91 & -1.72 & 48.23 & .513 \\
\hline
\end{tabular}

No significant difference between either methods of iron therapy as regard hemoglobin level, or iron parameters.

\section{Discussion}

The importance of intravenous (IV) iron as an adjunctive treatment had been increasingly recognized [14]. This is particularly true in hemodialysis patients, for whom iron losses are greater and IV iron supplementation often is necessary to optimize the erythropoietin activity. In some patients, IV iron may improve hemoglobin levels even before erythropoietin therapy is started, whereas concomitant use of IV iron along with EPO can enhance the erythropoietin response and reduce dose requirements of EPO. Data from studies have been pivotal in generating the recommendation in the revised European Best Practice Guidelines on renal anemia management that IV iron supplementation is likely to be required in all hemodialysis patients [15].

In our study 30 hemodialysis patients had iron deficiency anemia were divided into two matching groups for correction of iron deficiency, Group $A$ included 15 patients took a bolus intravenous iron administration protocol (total dose correction of iron) \& Group $B$ included 15 patients having an intermittent intravenous iron infusion protocol for 3 months. We used iron dextran in both groups calculating the amount of iron by mg needed by the following equation: (Target $\mathrm{Hb}$-Patient $\mathrm{Hb}$ ) $\mathrm{g} / \mathrm{l} \mathrm{X}$ body weight $\{\mathrm{kg}\} \times 0.24+$ Iron stores $\{\mathrm{mg}\} 500$ is recommended for iron stores in patients have body weight above $30 \mathrm{~kg}$ (www.medicines.org. uk/emc/ medicine/14139) Comparing between the two groups in the outcome of correction of anemia with fixed dose of erythropoietin injection of $100 \mathrm{mic} / \mathrm{kg}$ per week.

Patients Group $A$ who received total dose correction of iron The median hemoglobin $(\mathrm{Hb})$ level prior to infusion were $8.14 \mathrm{gm} / \mathrm{dl}$ and post-infusion significantly increased to $11.51 \mathrm{gm} / \mathrm{dl}(\mathrm{p}<0.001)$. Ferritin levels increased significantly from a median of $249.73 \mathrm{ng} / \mathrm{ml}$ pre-infusion to $596.33 \mathrm{ng} / \mathrm{ml}$ post-infusion $(\mathrm{p}<0.001)$, also TSAT (\%) significantly increased from 14.49 to $32.07(\mathrm{p}<0.001)$ \& there was insignificant decrease in CRP $7.60 \mathrm{mg} / \mathrm{dl}$ to $6.13 \mathrm{mg} / \mathrm{dl}(\mathrm{p}=0.036)$.

Patients Group $B$ who received total dose correction of iron The median hemoglobin $(\mathrm{Hb})$ level prior to infusion were $8.15 \mathrm{gm} / \mathrm{dl}$ and post-infusion significantly increased to $11.29 \mathrm{gm} / \mathrm{dl}(\mathrm{p}<0.001)$. Ferritin levels increased significantly from a median of $249.87 \mathrm{ng} / \mathrm{ml}$ pre-infusion to $598.33 \mathrm{ng} / \mathrm{ml}$ post-infusion ( $\mathrm{p}<0.001)$, also TSAT (\%) significantly increased from 15.01 to $30.97(\mathrm{p}<0.001)$ \& there was insignificant decrease in CRP $7.47 \mathrm{mg} / \mathrm{dl}$ to $6.73 \mathrm{mg} / \mathrm{dl}(\mathrm{p}=0.452)$.

There were no significant difference between either methods of iron therapy as regard correction of hemoglobin level or iron parameters or risk of infection on the short term period (Table 3). Our results were compatible with Fenwick and Peebles [16], who concluded in their retrospective study the effectiveness of high total dose correction of iron in achieving good levels of iron stores in HD patients and offering a strong alternative to the wide practice of frequent (e.g. weekly/fortnightly) lowdose supplementation (intermittent doses) in management of anemia. The Dialysis Patients' Response to IV Iron with Elevated Ferritin (DRIVE) I and II studies found that, in patients with high ferritin and low TSAT (a subgroup likely to be hypo responsive to 


\begin{tabular}{|c|c|c|c|c|c|c|c|}
\hline & & \multicolumn{3}{|c|}{ Bolus } & \multicolumn{3}{|c|}{ Intermittent } \\
\hline & & Mean & \pm SD & P Value & Mean & $\pm S D$ & P Value \\
\hline \multirow{2}{*}{$\mathrm{Hb}(\mathrm{gm} / \mathrm{dl})$} & Baseline & 8.14 & 0.43 & \multirow{2}{*}{$<0.001$} & 8.15 & 0.50 & \multirow{2}{*}{$<0.001$} \\
\hline & After & 11.51 & 0.52 & & 11.29 & 0.59 & \\
\hline \multirow{2}{*}{ Iron (mcg/dl) } & Baseline & 49.73 & 20.89 & \multirow{2}{*}{$<0.001$} & 54.00 & 22.56 & \multirow{2}{*}{$<0.001$} \\
\hline & After & 94.80 & 15.94 & & 91.67 & 12.47 & \\
\hline \multirow{2}{*}{ TIBC $(\mathrm{mcg} / \mathrm{dl})$} & Baseline & 333.20 & 78.03 & \multirow{2}{*}{0.088} & 352.27 & 88.21 & \multirow{2}{*}{0.047} \\
\hline & After & 293.07 & 43.36 & & 296.73 & 48.63 & \\
\hline \multirow{2}{*}{ TSAT (\%) } & Baseline & 14.49 & 3.77 & \multirow{2}{*}{$<0.001$} & 15.01 & 4.42 & \multirow{2}{*}{$<0.001$} \\
\hline & After & 32.07 & 3.24 & & 30.97 & 3.80 & \\
\hline \multirow{2}{*}{ Ferritin $(\mathrm{ng} / \mathrm{ml})$} & Baseline & 249.73 & 42.35 & \multirow{2}{*}{$<0.001$} & 249.87 & 43.89 & \multirow{2}{*}{$<0.001$} \\
\hline & After & 596.33 & 26.52 & & 598.33 & 25.70 & \\
\hline \multirow{2}{*}{ CRP (mg/dl) } & Baseline & 7.60 & 2.72 & \multirow{2}{*}{0.036} & 7.47 & 2.20 & \multirow{2}{*}{0.452} \\
\hline & After & 6.13 & 2.13 & & 6.73 & 2.66 & \\
\hline
\end{tabular}

ESA therapy), bolus administration of iron reduced ESA requirements and improved iron status and hemoglobin levels relative to no iron treatment $[17,18]$. In both DRIVE I and II, there were no increases in the risks of infection in the iron-treated groups.

Feldman and colleagues examined the effect of IV iron administration and mortality in a cohort of over 32,000 dialysis patients and did not found an association of cumulative dose of IV iron with mortality [19]. Another study of over 58,000 patients by KalantarZadeh and colleagues also did not find an association of iron dose with mortality, either all cause or cardiovascular mortality [20]. Rather, the administration of up to $400 \mathrm{mg}$ was associated with improved survival overall, and among many relevant subgroups. At doses greater than $400 \mathrm{mg}$, there was a trend towards increased mortality. Abhijit et al. [21], results complement and extend these previous studies. Like them, they did not find a consistent or meaningful association of IV iron with cardiovascular morbidity or mortality.

\section{Conclusion}

Patients with end stage renal disease on regular hemodialysis with iron deficiency anemia can be treated with intravenous iron administration either by the protocol of divided doses of IV iron through the sessions of hemodialysis or by giving the total dose of iron needed as a single large dose on only one session of hemodialysis, obtaining the same outcome in correction of iron parameters in treatment of iron deficiency anemia. However, additional safety concerns of IV iron administration, including potential infectious complications and long-term cardiovascular safety warrant further scrutiny.

\section{References}

1. Collins AJ, Li S, St Peter W, Ebben J, Roberts T, et al. Death, hospitalization, and economic associations among incident hemodialysis patients with hematocrit values of 36 to $39 \%$. J Am Soc Nephrol. 2001; 12: 2465-2473. Ref.: https://goo.gl/pc8Ad7

2. Besarab A, Coyne DW. Iron supplementation to treat anemia in patients with chronic kidney disease. Nat Rev Nephrol. 2010; 6: 699-710. Ref.: https://goo.gl/BnBSEf

3. Pfeffer MA, Burdmann EA, Chen CY, Cooper ME, de Zeeuw D, et al. A trial of darbepoetin alfa in type 2 diabetes and chronic kidney disease. N Engl J Med. 2009; 19: 2019-2032. Ref.: https://goo.gl/S8UVDm

4. Singh AK, Szczech L, Tang KL, Barnhart H, Sapp S, et al. Correction of anemia with epoetin alfa in chronic kidney disease. N Engl J Med. 2006; 355: 2085-2098. Ref.: https://goo.gl/CV2DWR

5. Robinson BM, Fuller DS, Bieber BA, Turenne MN, Pisoni RL. The DOPPS Practice Monitor for US dialysis care: Trends through April 2011. Am J Kidney Dis. 2012; 59: 309-312. Ref.: https://goo.gl/142wo9

6. Freburger JK, Ng LJ, Bradbury BD, Kshirsagar AV, Brookhart MA. Changing patterns of anemia management in US hemodialysis patients. Am J Med. 2012; 125: 906-914. Ref.: https://goo.gl/9WXsR4 
7. Charytan $D M, P a i A B$, Chan $C T$, Coyne DW, Hung $A M$, et al. Considerations and challenges in defining optimal iron utilization in hemodialysis. J Am Soc Nephrol. 2015; 26: 1238-1247. Ref.: https://goo.gl/LTNZrC

8. Wetmore JB, Peng Y, Monda KL, Kats AM, Kim DH, et al. Trends in anemia management practices in patients receiving hemodialysis and peritoneal dialysis: A retrospective cohort analysis. $\mathrm{Am} \mathrm{J}$ Nephrol. 2015; 41: 354-361. Ref.: https://goo.gl/s6RmSQ

9. Coyne DW, Kapoian T, Suki W, Singh AK, Moran JE, et al. Ferric gluconate is highly efficacious in anemic hemodialysis patients with high serum ferritin and low transferrin saturation: Results of the Dialysis Patients' Response to IV Iron with Elevated Ferritin (DRIVE) Study. J Am Soc Nephrol. 2007; 18: 975-984. Ref.: https://goo.gl/E4TEKS

10. Kshirsagar AV, Freburger JK, Ellis AR, Wang L, Winkelmayer WC, et al. The comparative short-term effectiveness of iron dosing and formulations in U.S. hemodialysis patients. Am J Med. 2013; 126 : 541. Ref.: https://goo.gl/yzkkeu

11. Thakuria M, Ofsthun NJ, Mullon C, Diaz-Buxo JA. Anemia management in patients receiving chronic hemodialysis. Semin Dial. 2011; 24: 597-602. Ref.: https://goo.gl/65Yj7u

12. Yong K, Kairaitis L. Effects of proactive iron and erythropoiesis-stimulating agent protocol implementation on achieving clinical guideline targets for anaemia in a satellite haemodialysis patient cohort. Nephrology (Carlton). 2010; 15: 288-293. Ref.: https://goo.gl/gzARxH

13. Besarab A. Anemia and iron management. Semin Dial. 2011; 24: 498-503. Ref.: https://goo.gl/efEXmw

14. Macdougall IC, Tucker B, Thompson J, Tomson CRV, Baker LR, et al. A randomized controlled study of iron supplementation in patients treated with erythropoietin. Kidney Int. 1996; 50: 1694-1699. Ref.: https://goo.gl/7JPnK9

15. Locatelli F, Aligama P, Barany P, Canaud B, Carrera F, et al. European Best Practice Guidelines Working Group. Revised European Best Practice Guidelines for the Management of Anaemia in Patients with Chronic Renal Failure. Nephrol Dial Transplant. 2004; 19: 1-47. Ref.: https://goo.gl/Q9aeBu

16. Fenwick S, Peebles G. Total dose infusion of intravenous iron in patients with chronic kidney disease receiving haemodialysis. Journal of Renal Care. 2011; 37: 47-51. Ref.: https://goo.gl/fUjn9R

17. Coyne DW, Kapoian T, Suki W, Singh AK, Moran JE, et al. Ferric gluconate is highly efficacious in anemic hemodialysis patients with high serum ferritin and low transferrin saturation: Results of the Dialysis Patients' Response to IV Iron with Elevated Ferritin (DRIVE) Study. J Am Soc Nephrol. 2007; 18: 975-984. Ref.: https://goo.gl/JwhQM9

18. Kapoian T, O'Mara NB, Singh AK, Moran J, Rizkala AR, et al. Ferric gluconate reduces epoetin requirements in hemodialysis patients with elevated ferritin. J Am Soc Nephrol. 2008; 19: 372-379. Ref.: https://goo.gl/Z2upWz

19. Feldman HI, Joffe M, Robinson B, Knauss J, Cizman B, et al. Administration of parenteral iron and mortality among hemodialysis patients. J Am Soc Nephrol. 2004; 15: 1623-1632. Ref.: https://goo.gl/9Tc7zt

20. Kalantar-Zadeh K, Regidor DL, McAllister CJ, Michael B, Warnock DG. Time-dependent associations between iron and mortality in hemodialysis patients. J Am Soc Nephrol. 2005; 16: 3070-3080. Ref.: https://goo.gl/KxPzSd

21. Abhijit VK, Janet KF, Alan RE, Lily W, Wolfgang CW, et al. Intravenous Iron Supplementation Practices and Short-Term Risk of Cardiovascular Events in Hemodialysis Patients. PLOS ONE. 2013. Ref.: https://goo.gl/NsBWDH 